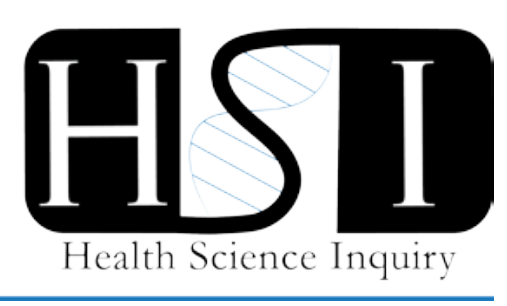

\title{
Wearable self-tracking technologies and hypertension: opportunities and challenges in the literature
}

\author{
Kathleen Slemon \\ Department of Psychology, University of Guelph
}

Wearable consumer self-tracking technologies (STT) automatically measure a host of variables such as geolocation, movement, mood, sleep, heart rate, breathing, and galvanic skin response with the intention of promoting self-awareness and positive behavioural changes [1]. Consumer self-tracking devices are regulated as "low risk" and are intended for general wellness and disease prevention (1), increasing their use in chronic care settings. This review article examines the literature on self-tracking and chronic conditions in order to better understand the risks and benefits to individuals with hypertension, and to identify further directions for research. Hypertension is a complex disorder that is often perceived as preventable and a result of individual inactivity, despite the host of psychosocial and genetic predictors that affect it [2]. Hypertension is often treated with a combination of medication, patient-targeted interventions and lifestyle changes, such as by increasing physical activity, managing stress, and reducing body weight [3]. Individuals with hypertension may turn to wearable STT to promote positive lifestyle changes, though little research has explored the benefits and risks of this practice.

The self-tracking literature thus far has been characterized as either techno-critical or techno-utopian, and the benefit and risks of self-tracking to individuals with hypertension will be reviewed. "Techno-critical" [4] research tends to view self-tracking technologies as surveillance devices that quantify complex bodily functions, while "techno-utopian" [5] perspectives tend to view self-tracking technologies as having the potential to support patients and health care professionals in disease management. This literature will be briefly reviewed in order to demonstrate the area where further understanding of the experiences of self-tracking in individuals with chronic conditions, such as hypertension, could be developed.

Wearable consumer self-tracking devices have been proposed to be tools that support those with chronic conditions such as hypertension, though little research has examined what that experience is like. Wang et al. [6] identified that users with FitBits increased their step count and total active minutes, which is a finding that could benefit those attempting to manage their hypertension or high blood pressure through lifestyle changes. Ayobi et al. [7] found that self-tracking physical activity supported patients with multiple sclerosis in maintaining or increasing their physical activity levels, and allowing them to feel more motivated and experience more hope in regard to their condition. STT provide longitudinal data for individuals with chronic illness, which can be beneficial to health care providers and in understanding their illness [8]. STT provide opportunities for patients with chronic conditions to objectively record their condition, and to relay that data to their health care professional.

While some evidence indicates that self-tracking can lead to positive outcomes for users, there is concern that the devices may have little benefit or even pose risks to users with hypertension or those who don't otherwise fit the definition of a "target user". Consumer devices have been criticized for lacking reliability [7], which may cause undue worry in users or a false senses of security [8] based on the data. Users with chronic conditions have expressed frustration that self-tracking devices aren't able to accurately capture their experience, and that the goals set by the devices may not be realistic for their differently abled bodies [7]. In Nunes et al.'s [9] critical review, it was found that in some conditions, such as hypertension, over-measuring of symptoms makes the condition worse or causes anxiety in patients. Interestingly, many users report simultaneous benefits and challenges of the devices, demonstrating that self-tracking is a complex practice that shouldn't be considered as inherently beneficial or problematic for a particular user. To conclude, further investigation into the experience of individuals with chronic conditions using STT is needed, particularly when considering the lack of research focusing on the experiences of users with hypertension. Currently there is little psychological understanding of STT impact on users with hypertension despite concerns about reliability and suitability. Additionally, while many researchers have criticized self-tracking for its lack of suitability for certain users or applauded its potential to increase efficiency in 
the healthcare system, further nuanced and exploratory work that showcases the experiences of users with complex and chronic conditions is needed. In particular, future research would benefit from a more in-depth exploration of the benefits and risks of self-tracking for users with hypertension.

\section{References}

[1] U.S. Department of Health and Human Services (2016). Wellness Policy for Low-Risk Devices: Guidance for Industry and Food and Drug Administration Staff. Retrieved from: https://www.fda.gov/downloads/medicaldevices/device regulationandguidance/guidancedocuments/ucm429674 .pdf.

[2] Levenstein, S., Smith, M. W., Kaplan, G. A. (2001) Psychosocial predictors of hypertension in men and women. Archives of Internal Medicine, 161 (10), 13411346.

[3] Heart and Stroke Foundation of Canada (2018). Fitness trackers help teens with heart disease. Available at: http://www.heartandstroke.ca/articles/fitnesstrackers-help-teens-with-heart-disease.

[4] Rio Carral, M., Roux, P., Bruchez, C., SantiagoDelefosse, M. (2016) Beyond the Debate on Promises and Risks in Digital Health: Analysing the Psychological Function of Wearable Devices. International Journal of Psychological Studies, 8 (4), 6-37. Available at: http://dx.doi.org/10.5539/ijps.v8n4p26.

[5] Rich, E., Miah, A. (2014) Understanding digital health as public pedagogy: A critical framework. Societies, 4 (2), 296-315.

[6] Wang, J. B., Cadmus-Bertram, L. A., Natarajan, L., White, M. M., Madanat, H., Nichols, J. F., Ayala, G. X., Pierce, J. P. (2015) Wearable sensor/device (Fitbit One) and SMS text-messaging prompts to increase physical activity in overweight and obese adults: a randomized controlled trial. Telemedicine and e-Health, 21 (10), 782-792.

[7] Ayobi, A., Marshall, P., Cox, A., Chen, Y. (2017) Quantifying the Body and Caring for the Mind. Proceedings of the $2017 \mathrm{CHI}$ Conference on Human Factors in Computing Systems. Available at: http://dx.doi.org/10.1145/3025453.3025869.

[8] Piwek, L., Ellis, D. A., Andrews, S., Joinson, A. (2016) The rise of consumer health wearables: promises and barriers. PLoS Medicine, 13 (2), e1001953.

[9] Nunes, F., Fitzpatrick, G. (2015) Self-care technologies and collaboration. International Journal of HumanComputer Interaction, 31 (12), 869-881.

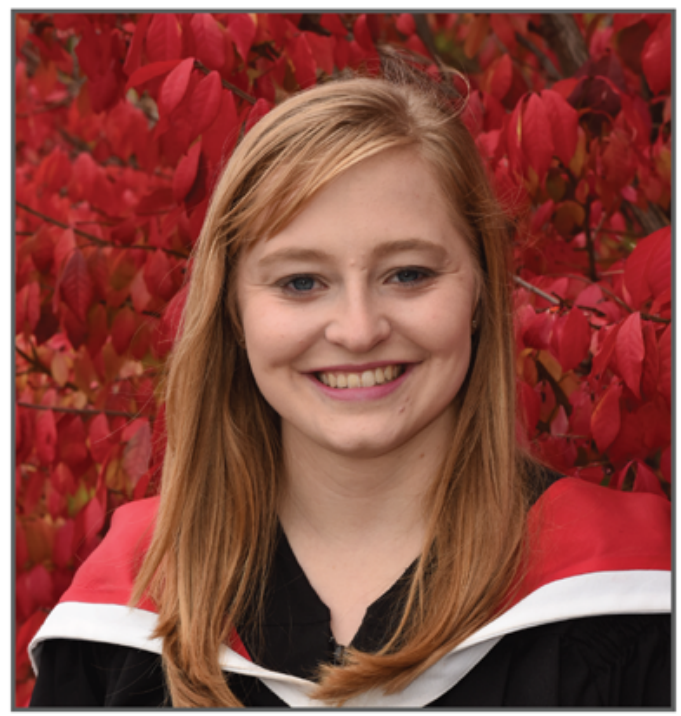

Kathleen is a Master's Candidate in the Applied Social Psychology program at the University of Guelph. Her Master's thesis examines how wearable self-tracking technologies enable users with high blood pressure or hypertension to understand their individual responsibility for health. 